R. R. Race, Aileen M. Prior and Elizabeth W. Ikin (Brit. Med. J., Feb. 24, 1940). It had already been shown that in some $A B$ cases the factor $B$ is partially dominant to and obscures the $A$ antigen; and that while there tends to be some weakening of the $B$ reaction in group $A B$, it is nothing like so marked or so important as is the suppression of $A$. As there are two types of $A$ antigen, $A_{1}$ and $A_{2}$, a stronger and a weaker, the suppression by $B$ of an already weak $A_{2}$ in the group $A_{2} B$ may result in it only being possible to detect the $A$ factor with powerful anti- $A$ serum, the cells otherwise being diagnosed as group $B$.

Following on the observations recorded, it is shown that the order of decreasing strength of reaction is $A, A_{1} B, A_{2}, A_{2} B$. Further, as the serum from quite a number of $A_{2} B$ cases contains the antibody $\alpha_{1}$, which reacts with $A_{1}$ but not with $A_{2}$ cells, unless appropriate measures are taken, a reaction will result which confirms the diagnosis of group $B$. In view of the significance attached in anthropological classification to the distribution both within a given population and geographically of the elements $A$ and $B$, it is of interest and importance to note that cases diagnosed as $B$ have been found on re-examination to belong to group $A B$, and an inspection of published figures from all parts of the world shows that in a large proportion of the series there is a real deficiency of the numbers in group $A B$. It is possible that herein lies a clue to the explanation of certain anomalies and apparent irregularities to be noted in studies of the groups as racial elements.

\section{The Black Rat in Great Britain}

Nor so long ago it was generally said that the black rat, Rattus rattus, had disappeared from Britain, ousted in unequal contest with the brown new-comer, Rattus norvegicus. But to most naturalists interested in the subject it was known that little centres existed in wide-scattered areas where a black rat could be found if it was wanted. Now Colin Matheson, in an interesting account of results derived from his own observations in Cardiff and from a questionnaire sent to medical officers of health in "approved ports", discloses a somewhat disturbing situation about the black rat, the carrier of the flea, which in its turn disseminates plague (J. Anim. Ecol., $8,76 ; 1939)$. Stringent regulations are in force to ensure that ships are kept free of rats, and that while ships are in port it should be made extremely difficult for inboard rats to make a passage to the shore. The result has been a general decline in the rat population of ships visiting Britain, although a number averaging $6-8$ seems to be the irreducible minimum on rat-infested ships.

On shore, however, in spite of rat-weeks and ratprevention measures, the number of black rats appears to be on the increase, the statistics for thirteen British seaports showing a rise from about 4,110 in 1929 to more than 6,437 in 1934 and 5,362 in 1937. Moreover, the shore companies appear to be extending their range from the neighbourhood of docks to city areas, in some of which they are well established, and are able to maintain themselves without further accessions from the dockyard immigrants. Of the three commonest races of the black rat the most. frequent in British seaports is the typical black form, $R$. $r$. rattus, but curiously enough the brownish $R$. $r$. alexandrinus takes the lead in numbers in London and Plymouth.

\section{Activities of Analytical Chemists}

In his presidential address to the Society of Public Analysts and other Analytical Chemists delivered on March 6, Prof. W. H. Roberts pointed out that there has been much less need in this War than in the last for the formation of ad hoc committees of chemists to deal with problems with which the Government departments found themselves faced, for much had been foreseen and provided for ; and some of the departments had from the outset adopted the course of appointing to their staffs eminent outside chemists, who not only brought to the departments their own expert knowledge but also rendered the departments more accessible to suggestions and representations from outside chemical bodies. The compilation of the National Service Register by the Ministry of Labour, in which the Society had co-operated, had provided the Government with a source of specialized personnel. The conditions of appointment of gas identification officers needs reconsideration, especially in view of the duties now placed upon them in respect of preliminary food tests for gas-contamination. Referring to the Food and Drugs Act of 1938, Prof. Roberts said that the rationing of meat would probably lead to increased consumption of certain other foods, such as sausages and cheese, and regulations governing the content of meat in sausages and of water in cheese (particularly processed cheese) would therefore become very necessary.

The number of analysts and consultants in independent practice has diminished greatly in recent years, Prof. Roberts said, but in the public interest it is important that there should be a strong band of such chemists, not attached to any special interest, and it was therefore necessary to watch closely for cases of unfair competition by publicly supported laboratories. Speaking of the necessity of maintaining a high standard of efficiency amongst analysts, he expressed regret that no English university has yet inaugurated a chair of analytical chemistry, and also suggested that the universities should exercise more rigorous selection to ensure that only students having a real aptitude for the subject should be admitted to their courses. The roll of the Society now includes 886 names. The following officers for the year 1940-41 were elected : President, Dr. E. B. Hughes ; Hon. Treasurer, G. Taylor ; Hon. Secretary, Lewis Eynon.

\section{The Ray Society}

AT the annual general meeting of the Ray Society held on March 5, under the presidency of Sir Sidney Harmer, Lieut.-Colonel R. B. Seymour Sewell was elected a vice-president and Sir David Prain, Dr. R. W. T. Gunther (since deceased) and Mr. C. S. Todd new members of 